\title{
IMPROVING OCCUPATIONAL HEALTH AND SAFETY AND IN THE HOME- BASED FOOTWEAR INDUSTRY THROUGH IMPLEMENTATION OF ILO-PATRIS, NOSACQ-50 AND PARTICIPATORY ERGONOMICS: A CASE STUDY
}

\author{
Paulus Sukapto ${ }^{1}$, Johanna Renny Octavia ${ }^{1 *}$, Putu Ayu Diah Pundarikasutra ${ }^{1}$, \\ Paulina Kus Ariningsih ${ }^{1}$, Sani Susanto ${ }^{1}$ \\ ${ }^{1}$ Universitas Katolik Parahyangan, Jl. Ciumbuleuit No.94, Bandung 40141, Indonesia
}

(Received: April 2019 / Revised: June 2019 / Accepted: September 2019)

\begin{abstract}
The footwear industry in Indonesia is considered important as it is one of the largest contributors to employment and income for the country. Besides the formal manufacturers, the sector also comprises informal or home-based ones. More than 50\% of this home-based footwear industry in Indonesia is located in Cibaduyut, Bandung. The main issues related to it are the lack of awareness of the risks embeded in the work environment, and the safety and ergonomics of the employees. Therefore, research was conducted to evaluate these aspects in order to ensure the future sustainability of the industry. Three questionnaires were employed for the study, the Participatory Action Training for the Informal Sector (PATRIS) questionnaire, the Nordic Safety Climate Questionnaire (NOSACQ-50) and the Employee Perceptions of Participatory Ergonomics Questionnaire (EPPEQ), in order to evaluate safety and ergonomic practice related to current activities, based on four representative shoe workshop samples. The ILO-PATRIS checklist shows that the four shoe workshops require improvements in both their facilities and working environments $(\mathrm{p}<0.01)$. The NOSACQ-50 analysis shows that the safety climate levels of employees were $84 \%$ low and $16 \%$ moderate, while those of owners were $27 \%$ low and $73 \%$ moderate. This shows a significant difference between the safety climates of employees and owners $(\mathrm{p}<0.05)$, with a strong relationship $(\mathrm{r}=0.88)$. The ergonomic analysis of employee participation based on EPPEQ shows that all workers displayed acceptable levels. However, linear regression analysis shows that ergonomic activity has no significant relationship with facilities, work environment or work safety climate ( $p>0.05)$. ILO-PATRIS complements NOSACQ-50 in measuring the safety climate of small and medium sized enterprises, especially home-based shoe workshops. Overall, the four shoe workshops need to improve their working environment, work facilities, safety climate and participatory ergonomics of the employees.
\end{abstract}

Keywords: Home-based shoe workshops; Participatory ergonomics; Work safety climate; Workplace hazards

\section{INTRODUCTION}

Indonesia's footwear industry ranks fifth amongst world exporting countries, after China, India, Vietnam and Brazil, with a share of the international market of 4.4\% (Julianto, 2017). As one of Indonesia's most productive economic industries, the footwear sector is divided into two categories: formal (licensed) and informal (unlicensed) home-based manufacturers.

In practice, the informal sector is less concerned with the aspects of facilities provided, work

*Corresponding author's email: johanna@unpar.ac.id, Tel. +62-22-2032655, Fax.+62-22-2032700

Permalink/DOI: https://dx.doi.org/10.14716/ijtech.v10i5.3033 
environment and safety. Furthermore, home-based manufacturers recruit employees who have excellent skills in shoemaking without prioritizing the status of their education (ILO, 2004).

The Government Regulation of the Republic of Indonesia Number 50 of 2012 concerning Occupational Safety and Health (K3) requires that the safety and health of workers is ensured through the prevention of occupational injuries and diseases. In Indonesia, the protection of employee rights was already included in the Constitution of Work Safety Act No.1 of 1970. This law covers all workplaces and emphasizes primary prevention. Moreover, the recently passed Manpower Act (Law No. 13 of 2003) refers to Articles 86 and 87; all owners are required to provide their employees with a minimal level of protection. ILO (2013) also reports that unorganized workplaces may pose potential hazards and harm, and also threaten the health of employees. This could consequently reduce employee income and will certainly reduce the productivity of the company (ILO, 2013). Previous studies have shown the importance of measuring conditions in the working environment as a basis for ergonomic interventions and workplace improvements to ensure worker safety and health (Siswanto et al., 2017; Iridiastadi et al., 2019).

Cibaduyut, Bandung in Indonesia is a provincial sub-region that contains industrial complexes and is home to a large number of home-based footwear manufacturers. In the region, footwear companies have been controlled by families for generations. Many employees are found to be in the low-age and low-education categories, with related factors reported to affect awareness of work safety and hazards in the workplace (Markkanen, 2004). Accidents occur as a result of the interaction of several sequential events within a system.

PATRIS was developed by the ILO to enhance safety in the informal SMME sector in third world countries. PATRIS training for the informal footwear industry has already being implemented in Indonesia in 2002 (ILO, 2003). In 2003, ILO Indonesia required that home-based manufacturers in Cibaduyut must comply with PATRIS; however, these practices have not been widely implemented due to the lack of participation from the employees and owners of existing homebased facilities. In 1999, ILO-IPEC conducted a study of 456 of the 1,132 shoe workshops in the Cibaduyut area, with the focus on work-related hazards (the continuing existence of poor ventilation), chemical handling practices, and fire prevention (ILO, 2003). With regards to work safety, poor ergonomic activities and standard operating procedures for the use of machines or tools were threatening the safety of the operators (employees). The set of problems described above poses a challenge for the development of the informal industrial sector, especially in relation to the process of maintaining the quality and frequency of production and ensuring the safety of the work environment.

The main cause of accidents is the presence of potential hazards. In other words, accidents are not only caused by the unsafe behavior of humans, but also by mistakes made by decision-makers, with the consequence that potential accidents are delayed until triggered by human error. Participatory ergonomics is one of the research tools used in this study to analyse safety and work environment hazards. This can provide a participative solution to employees and owners to improve various aspects of the problem. Moreover, the focus is to ensure that the footwear production runs efficiently, economic rotation activities remain stable, and investment increases in the future. The analytical part of the study uses the participatory ergonomics approach to aspects ranging from the identification of safety problems, to suggestions made to the company.

Participatory ergonomics involves the active involvement of employees in implementing ergonomic knowledge and procedures in the workplace, which is supported by managers and supervisors. Seim and Broberg (2010) define participatory ergonomics as human involvement in the planning and controlling of most work activities, with sufficient power and knowledge to influence the process, resulting in achievement of the desired goal of an increased sense of 
responsibility for industrial or organizational activities, and of the goal of improved institutional productivity. Workplace hazards have been evaluated by the ILO-PATRIS checklist, used as a tool to improve working conditions in the informal shoe workshop sector (ILO, 2003). The checklist focuses on workplace hazards, preventive measures and day-to-day management practices relevant to informal shoe workshops. The safety climate in the such workshops is ensured by the shared perceptions of members of the social unit of safety-related policies, procedures and practices within the organization. This climate provides a framework for guiding workers' safety behaviour so that they will build perceptions and expectations regarding the impact of such behaviour (Dov, 2008). NOSACQ-50 is used to measure the safety climate developed by safety researchers based on organizational climate theory and safety, psychological theory, previous empirical research, and empirical results obtained through international studies and development processes (Kines et al., 2011). It consists of 50 statements divided into seven dimensions. In addition, EPPEQ has been used to measure the ergonomics of participation in workshops to identify program areas that need to be improved (Matthews et al., 2011).

While PATRIS has been applied widely, the safety climate is rarely checked, even though measurement of it is needed as a first step to achieve the participatory ergonomics, especially in SMMEs. NOSACQ-50 is currently widely used to measure the safety climate in industry. PATRIS is used to measure the eligibility of safety on the facilities and systems, while NOSACQ-50 is used to measure the perception of the safety climate amongst workers. Implementation of participatory ergonomics is enriched by input from the NOSACQ-50 safety climate. At last, participatory ergonomic activity is measured to understand its performance and can thus improve an organization's safety level. This paper aims to propose an increased safety environment in the informal footwear industry by sequencing measurement by PATRIS (risk assessment), NOSACQ50 (safety climate), and EPPEQ (participatory ergonomics).

\section{METHODS}

The study evaluates the characteristics of home-based manufacturers in terms of employee safety and workplace risk assessment. The results obtained from interviews and direct observations made at selected shoe workshops identify the problem, supported by the history of the employees and a literature review. Identification of problems is oriented towards owners and employees based on organizational activity.

\subsection{Population and Sample}

Four shoe workshops were selected as representative of the large number of informal footwear workshops in Cibaduyut, Bandung, Indonesia. They are labelled A, B, C and D. While A, B and $\mathrm{C}$ are classified as small-scale production units, $\mathrm{D}$ is classified is a large-scale production unit. Workshop A has six employees producing 80-100 pairs of shoes a week; B has eight employees producing 200-300 pairs of shoes a week; $C$ has 15 employees producing 400-600 pairs of shoes a week; and D has 22 employees producing 500-600 pairs of shoes a week. The operating times of all the workshops are identical, roughly 7-12 hours a day. They all have a variety of work facilities based on the standards of footwear manufacture. Filling the capacity and capability gap among the shoe workshops is mutually beneficial for supporting production. Workshop D does not have a skiving machine; workshop $\mathrm{C}$ does not have a press machine, while none has a rivet machine. Workshops B and D each have an oven and there are machines in A and D that provide punching mechanisms.

\subsection{Survey Instrument}

Workplace risk assessment and management was conducted using PATRIS. This instrument evaluated the feasibility of physical, building and welfare facilities, ergonomics, work equipment, work organization, personal safety equipment and day-to-day management practices. Assessment 
is based on the following scores: 0 (major change), 1 (moderate change) and 2 (excellent) (ILO, 2003). A work climate safety study was conducted using NOSACQ-50, an instrument which applies seven dimensions of assessment (Kines et al., 2011); dimensions 1 to 3 evaluate management related to safety, while dimensions 4 to 7 evaluate workers' safety reliability. The evaluation of ergonomic participation was conducted using EPPEQ.

\subsection{Data Collection}

The data was collected by a questionnaire through the in-depth interview approach. The focus of the data collection was based on management problems occurring in the four selected shoe workshops. In this study, the four shoe workshops were tested using the ILO-PATRIS checklist, which includes the evaluation of the physical environment, buildings and welfare facilities viewed from the ergonomic angle, followed by work equipment, work organization, personal protection equipment and finally the management of daily activities.

\subsection{Statistical Analysis}

A paired t-test was conducted to test the hypotheses on this study $(\mathrm{p}<0.05)$. The correlation $(r=$ 1) measured the strength of the linear relationship between two quantitative variables, while linear regression analysis was performed to examine the association among variables.

\section{RESULTS AND DISCUSSION}

\subsection{Questionnaire Response}

A number of evaluations were used to link the workshop environment profile to worker safety and ergonomic conditions. An overview of shoe workshop activities based on the ILO-PATRIS checklist can be seen in Figure 1.
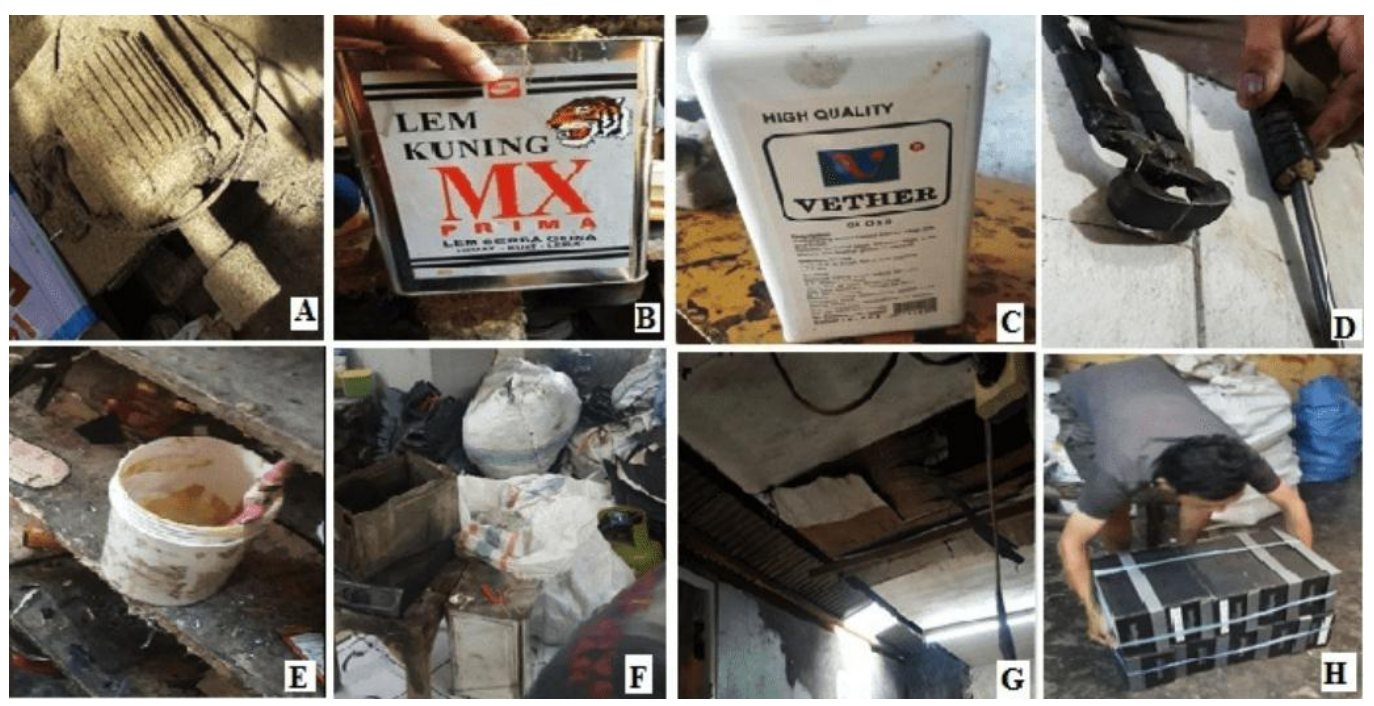

Figure 1 Shoe workshop profile; (a) Machines with thick dust; (b) Shoe glue; (c) Shoe paint chemicals; (d) Work tools; (e) Chemical brushes and containers; (f) Landfill; (g) Workplace ventilation; (h) Manual lifting of goods

The PATRIS check sheet was subsequently assessed using scoring, ranging from 0 (lowest score) to 1 (highest score). The results of this assessment will indicate priorities for improvement based on the calculation of the Index Priority Ratio (IPR). The IPR value is obtained by calculation of the ratio between the number of statements in one category with a value of 0 and the total number of statements in that category. Figure 2a shows that based on this value, the four workshops need improvements. The results of the Pearson correlation analysis show that the workshops were significantly different $(\mathrm{p}<0.01)$, with very strong relationships, as shown in Table 1 . This means that they have individual advantages and disadvantages, but still need improvement based on the 
PATRIS checklist. The correlation is shown to be significant at the 0.01 level (2-tailed) and the Pearson correlation (1.00) are seen as strong. Workshops A and B have $\mathrm{p}<0.001 ; \mathrm{r}=0.992$; workshops $\mathrm{A}$ and $\mathrm{C}$ have $\mathrm{p}<0.001 ; \mathrm{r}=0.951$; and workshops $\mathrm{A}$ and $\mathrm{D}$ have $\mathrm{p}<0.001 ; \mathrm{r}=0.961$. In addition, workshops $\mathrm{B}$ and $\mathrm{C}$ have $\mathrm{p}<0.001 ; \mathrm{r}=0.972$ and workshops $\mathrm{B}$ and $\mathrm{D}$ have $\mathrm{p}<0.001$; $\mathrm{r}=0.941$.

The reliability test for the NOSACQ-50 questionnaire shows that the reliability value for all dimensions already has a Cronbach's Alpha Coefficient value of $>0.7$ (see Figure 2b), which is considered ideal. Dimensional analysis was then conducted on the workers and owners by averaging the values of the NOSACQ-50 questionnaire.

Table 1 Frequency and distribution of work safety climate value based on scales by paired t-test analysis with the Pearson correlation

\begin{tabular}{ccccccccc}
\hline \multirow{2}{*}{ Dimension } & \multicolumn{9}{c}{ Owners } & \multicolumn{2}{c}{ Employees } & \multirow{2}{*}{$\mathrm{p}$} & $\mathrm{r}$ \\
\cline { 2 - 7 } & Safety Value & Scale & Freq & Safety Value & Scale & Freq & & \\
\hline 1 & 2.75 & Quite low & $14 \%$ & 2.62 & Low & $14 \%$ & & \\
2 & 2.79 & Quite low & $14 \%$ & 2.67 & Low & $14 \%$ & & \\
3 & 2.75 & Quite low & $14 \%$ & 2.64 & Low & $14 \%$ & & \\
4 & 2.67 & Low & $14 \%$ & 2.59 & Low & $14 \%$ & p $<0.05$ & 0.88 \\
5 & 2.64 & Low & $14 \%$ & 2.53 & Low & $13 \%$ & & \\
6 & 2.97 & Quite low & $15 \%$ & 3.08 & Passable & $16 \%$ & & \\
7 & 2.75 & Quite low & $14 \%$ & 2.65 & Low & $14 \%$ & & \\
\hline
\end{tabular}

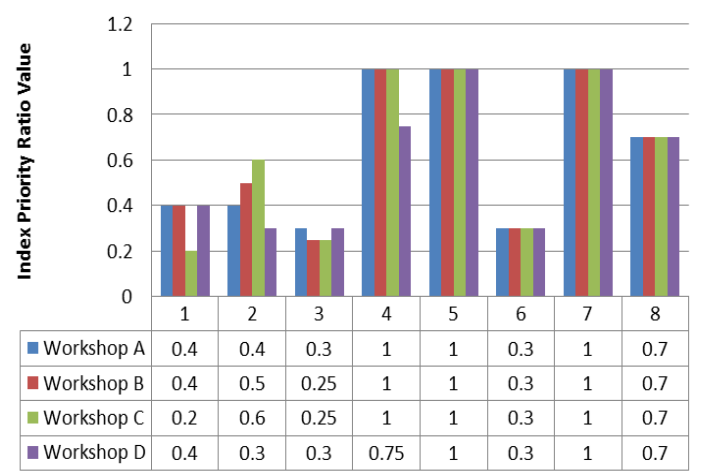

(a)

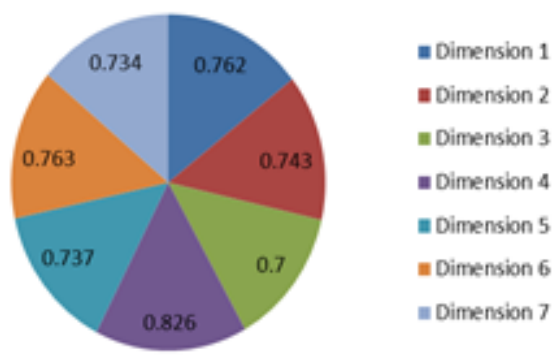

(b)

Figure 2 (a) Index priority ratio of shoe workshops; (b) Reliability value of the work safety climate evaluated by NOSACQ-50

The average calculation refers to NRCWE (2014), with average values of $>3.3$ (all dimensions are good); 3.0-3.3 (levels are sufficient); 2.7-2.99 (levels are quite low); and 2.7 (low level). The results of the study show the seven dimensions of the owner ranging in the level of low (with a frequency of 27\%) and quite low (73\%), while workers are ranging in level of low (frequency of $84 \%)$ and quite good (16\%). Based on these values, the safety climate needs to be improved, as shown in Table 2.

Figure 3a shows that the average value of statements 1 to 17 is above 3; statements 15 and 17 have a value below 3 . In general, the ergonomic participation activity of workers is sufficient. This activity, as seen in Figure $3 b$, was not significantly different from the shoe workshop facilities, work environment and work safety climate $(\mathrm{p}>0.05)$. 
Table 2 Linear regression (bivariate and multivariate analyses) on the relationship between ergonomic activity, work safety and shoe workshop facilities

\begin{tabular}{llllllll}
\hline \multirow{2}{*}{$\begin{array}{c}\text { Dependent } \\
\text { factor }\end{array}$} & $\begin{array}{c}\text { Independent } \\
\text { factors }\end{array}$ & $\mathrm{N}$ & Mean \pm SDV & $\begin{array}{c}\text { Coeffi- } \\
\text { cient }\end{array}$ & $\begin{array}{c}\text { Coeffi- } \\
\text { cient } \\
\text { correla- } \\
\text { tion }\end{array}$ & $\mathrm{p}$ & $\mathrm{r}$ \\
\hline \multirow{2}{*}{$\begin{array}{l}\text { Ergonomic } \\
\text { activities }\end{array}$} & Work safety & 14 & $2.72 \pm 0.148$ & 0.22 & 0.28 & $\mathrm{p}>0.05$ & 0.279 \\
\cline { 2 - 8 } & $\begin{array}{l}\text { Workshop } \\
\text { facilities and } \\
\text { environment }\end{array}$ & 32 & $0.63 \pm 0.311$ & 0.124 & 0.342 & $\mathrm{p}>0.05$ & 0.201 \\
\hline
\end{tabular}

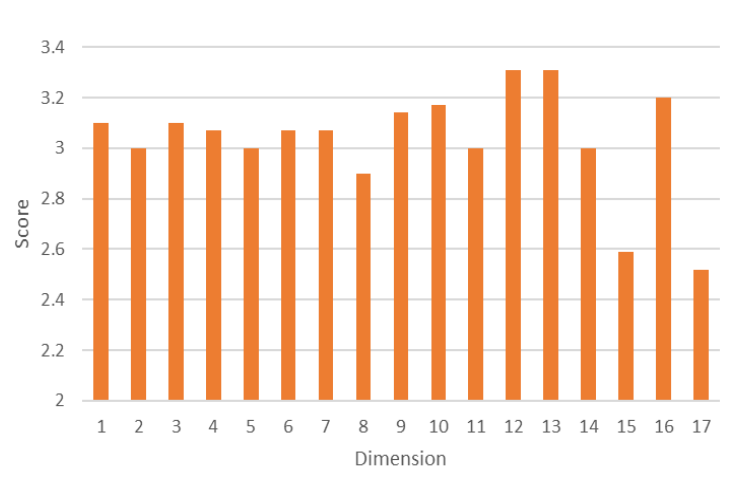

(a)

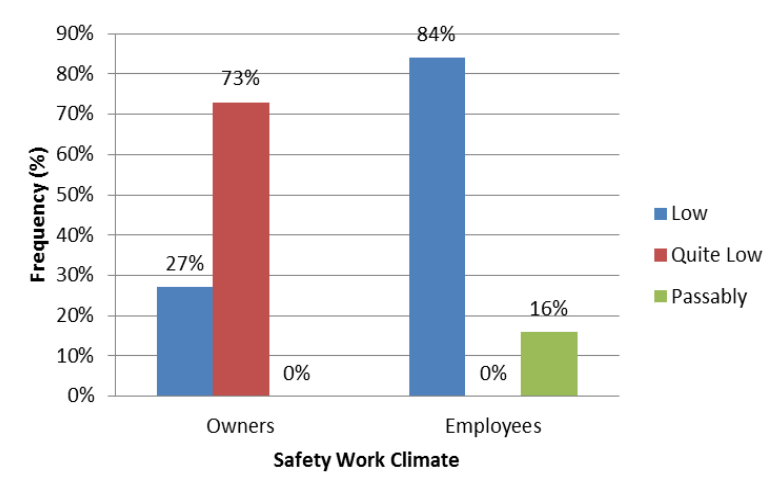

(b)

Figure 3 (a) Evaluation of participatory ergonomics of workers; (b) Dimension of work safety climate

\subsection{Discussion}

ILO-PATRIS (Joint Action Training for Actors in the Informal Sector) is a method created by the ILO and was implemented in 2003 to help evaluate the home footwear industry in Cibaduyut. It was used to evaluate the environment of shoe workshops, and has shown that in general the work environment is less than ideal (see Figure 1), with dust produced as the result of cutting (thinning) and the cutting process.

This dust has a size of $1-3 \mu \mathrm{m}$, which means it is very difficult to clean and very easy to enter the lung alveoli, so it can have an effect on the health of workers (Decree of the Minister of Health of the Republic of Indonesia Number 1405/Menkes/SK/XI/2002). In addition, evaluation of chemicals such as benzene, toluene, xylene is often performed in shoe making. These three ingredients are organic solvents contained in the composition of glue and can have a negative impact on human health, including damage to the nervous system, skin, liver, kidneys, immune system and lungs. The chemicals are also flammable (Markkanen, 2004) and can be seen as potential hazards.

Based on observation, workers tend to clean the glue with gasoline or kerosene, which increases the exposure to benzene and toluene in the body (Lim et al., 2014). In general, the machines used do not make noise, but the hammer blows in the manufacturing process are very hard and can interfere with concentration while working. Additionally, the four workshops have hot workspaces; according to the Decree of the Minister of Health of the Republic of Indonesia Number $1405 / \mathrm{Menkes} / \mathrm{SK} / \mathrm{XI} / 2002$, the recommended temperature for workplaces is $18-28^{\circ} \mathrm{C}$. Furthermore, the workspaces are poorly ventilated. The buildings used for shoe workshops generally do not have fixed standards for storage and handling, workplace maintenance, waste disposal or fire prevention strategies. Fires form one of the serious potential hazards for the workshops, as they contain many chemicals that are flammable. In addition, smoking in the 
workplace is one of the causes of fire. Workers' awareness programs are needed in an effort to prevent such fires (Penman et al., 2011).

The results of the ergonomic evaluation of all the shoe workshops indicate that there are no standard seats or work tables, meaning many workers use the existing facilities; for example, at the lasting station workers use their own thighs to make the shoes. The use of the thigh makes the worker bend while working, so the back and neck become sore. Thighs used as a placemat or work surface can cause injury to the thighs themselves, hands and fingers. In addition, workshop workers have not received information related to appropriate methods of lifting material. They lift goods by bending their backs, which can cause back pain. A good lifting posture is assumed when the back of the worker remains upright and the hips are lowered when picking up items. Therefore, Abraham et al. (2004) suggest that in various work actions there needs to be strategic communication to workers; for example, the provision of an ergonomics workbook so that workers have positive awareness of the use of work tools or facilities.

The observations also revealed that all the shoe workshops use work tools that can endanger workers; for example, those used in the cutting process, rounding process, assembly process and the process of making the upper part of the shoe. These dangerous tools include scissors, hammers, skiving machines, and knives. If workers are not careful when performing the work process, injuries can be caused. These can occur on the thighs, fingers and hands of workers. The various tools used such as knives and scissors are sharp objects that can cause injury, and hammers can also cause injury to the thighs or fingers. According to Al-Thani et al. (2014), traumas in the workplace have a negative impact on the health of workers, and the incidence of these has increased, especially among new workers. In general, workplace injury is the main source of disability and death, which in turn will cause serious problems for the welfare of the families of workers who die as a result of workplace accidents (Nagai et al., 2007).

In addition, all the workshops only provide masks, while other personal protective equipment such as shoes and gloves are not provided. The companies should therefore also provide free gloves, which can protect workers' hands from direct contact with chemicals. In addition to personal protective equipment, companies need to undertake good work safety management.

The first dimension of the NOSACQ-50 calculation shows a fairly low level, indicating that the workers consider safety management in the work environment to be insufficient, or even a fairly low priority for the owners. Calculation of safety climate statements numbers 1 to 9 produces an average of $>2.5$, although statement number 5 attains a value of 2.29. The average safety climate value of $>2.5$ is significantly positive, but still needs improvement (Ajslev et al., 2017). In the workers' perspective, toward the owner is that management is still orienting to production by compromising of the safety of employees. Mohammadfam et al. (2017) reports that attention paid to health and a good management system plays an important strategic role in health and safety in the workplace.

The second dimension has an owner's work safety climate value of 2.79, with that of the workers of 2.67, meaning both are categorized as quite low levels. Workers and owners have the perspective that they still feel uneasy to empowering safety. The owners feel that they are making a sufficient effort to support workers in achieving high competencies related to safety and the risk of danger. In fact, the workshop owners themselves do not have adequate competency in these fields. They do not make a sufficient effort to seek knowledge about safety and risk of hazards in the workshop, which makes the workers very vulnerable to dangerous situations, and hazardous situations are more likely to occur, especially as a result of the chemicals used for the production process (Lalko et al., 2011).

The third dimension has an average safety climate value for workers of 2.64 (low) and for owners 2.75 (quite low). In this dimension, workers feel that the owners' ability to manage safety 
regulations is still at a low level. At the same time, the owners also feel that their ability to manage safety-related regulations is quite low.

In dimension four, the workers' safety climate value is 2.59 (low) and for owners it is 2.67 (low). This dimension considers the commitment of workers to safety. Based on the average value, it can be assumed that their commitments, and that of owners, are equally low. Workers try to work safely when undertaking their daily tasks; for example, the application of glue as in figure 1 is made inconsistently by using unprotected hands. Applying glue using one's bare hands is a dangerous activity because the chemicals contained in the glue cause irritation to the skin and itching if there is continuous exposure (Ackermans et al., 2012).

In dimension five, the safety climate value of workers is 2.53 and that of owners 2.64. Both are low. This dimension concerns the priority of workers towards safety and denial of the risk of danger. Based on the average values above, it can be concluded that the owners consider that workers do not prioritize a safety culture when working, and continue to deny the risk of dangerous environmental conditions and unsafe actions performed by workers. This safety culture needs to be improved by every worker in order to avoid work accidents, and the safety climate will be considerably improved by changing the climate from a compulsion into awareness for every worker. Finally, a work safety culture can gradually become a matter of awareness for all workers and subsequently lead to a national policy (Kim et al., 2016), especially in homebased industries with a work safety culture that tends to receive less attention from owners.

In dimension six, the worker safety climate value is 3.08 and that of the owners 3.0 , both of which are quite good. This dimension relates to the communication with and to the trust of workers in the occupational safety experts and what they learn from them. The level is high enough to show that workers and owners believe in safety experts.

Finally, in dimension seven workers have an average safety climate value of 2.65 (low), whereas that of the owners is 2.75 (sufficient). In this dimension, the workers' trust in the effectiveness of the existing safety system at the workplace is considered. From the average values, it can be understood that the trust of workers and owners in the effectiveness of such systems is quite low. In general, informal industries (home industries) have a history that is far from positive for workers; besides, the limited funds from the company owners are still controlling the safety costs (Listyani \& Faisal, 2014).

Analysing both PATRIS and NOSACQ-50, it is clear that several dimensions of the former are considered low, which may lead to low NOSACQ-50 scores. Therefore, improvements are suggested through the implementation of ergonomic participation. According to Van Eerd et al. (2010), this is the active involvement of workers in implementing knowledge and ergonomics in the workplace, supported by managers and supervisors. In its application to this research, the first step is to introduce ergonomics and ergonomic participation to workers and workshop owners in the hope that they will gain adequate knowledge of the concepts, thus simplifying the analysis of the relationship between ergonomic participation in the work environment and workshop facilities, and their relationship to work safety. In this regard, the role of workers and organizational owners is important in supporting health and safety supervision for workers.

Figure 3 shows that ergonomic activity has attained a high value, even though the linear regression analysis does not show a relationship to the variable facilities, workplace environment and worker safety. Ergonomic evaluation aims to identify work stations that need improvement (Matthews et al., 2011). This indicates that ergonomic activity arises from the awareness of the workers themselves to always be vigilant in their different work actions, even if the owner does not provide facilities and infrastructure. Nevertheless, this requires an element of professional intervention in the field of macro ergonomics to balance ergonomic activities with work safety, workplace support facilities and the surrounding environment. 


\section{CONCLUSION}

ILO PATRIS complements NOSACQ-50 in measuring the workplace safety climate when assessing industrial areas which consist of multi-workshops. PATRIS portrays specific problems in the safety facilities inside the system, while NOSACQ-50 shows the perception of safety within it. This method clearly gives a complete picture of the safety conditions inside the system, thus ensuring the success of participatory ergonomics as a tool to improve the work safety climate, especially whenever problems are only vaguely identified. The measurement of EPPEQ describes how well the interior participatory ergonomic system has been implemented; its validity is shown by the measurement of small and medium sized footwear industry centers.

Based on the measurement by PATRIS, NOSACQ-50 and EPPEQ of the four shoe workshops, it is concluded that there is a need for improvement in the working environment, work facilities and work safety climate. The ergonomic activity of participation of the employees is generally sufficient, but this still needs to be improved, as based on the linear regression analysis there is no significant association between the ergonomic activity of participation and the facilities, environment and work safety climate.

\section{REFERENCES}

Abraham, J., Feldman, R., Carlin, C., 2004. Understanding Employee Awareness of Health Care Quality Information: How Can Employers Benefit? Health Services Research, Volume 39(6), pp. 1799-1816

Ackermans, P.A., Solosko, T.A., Spencer, E.C., Gehman, S.E., Nammi, K., Engel, J., Russell, J.K., 2012. A User-friendly Integrated Monitor-adhesive Patch for Long-term Ambulatory Electrocardiogram Monitoring. Journal of Electrocardiology, Volume 45(2), pp. 148-153

Ajslev, J., Dastjerdi, E.L., Dyreborg, J., Kines, P., Jeschke, K.C., Sundstrup, E., Jacobsen, M,D., Fallentin, N., Andersen, L.L., 2017. Safety Climate and Accidents at Work: Cross-sectional Study Among 15,000 Workers of the General Working Population. Safety Science, Volume 91, pp. 320-325

Al-Thani, H., El-Menyar, A., Abdelrahman, H., Zarour, A., Consunji, R., Peralta, R., Asim, M., El-Hennawy, H., Parchani, A., Latifi, R., 2014. Workplace-related Traumatic Injuries: Insights from a Rapidly Developing Middle Eastern Country. Journal of Environmental and Public Health, Volume 2014, pp. 1-8

Dov, Z., 2008. Safety Climate and Beyond: A Multi-level Multi-climate Framework. Safety Science, Volume 46(3), pp. 376-387

ILO, 2003. Improving Safety, Health and the Working Environment in the Informal Footwear Sector. Indonesia

ILO, 2004. Child Labour in the Informal Footwear Sector in West Java, Indonesia. Indonesia

ILO, 2013. Safety and Health Work at Workplace. Indonesia

Iridiastadi, H., Anggawisnu, B., Didin, F.S., Yamin, P.A.R., 2019. The Prevalence of Musculoskeletal Complaints among Hospital Nurses and Nursing Home Caregivers in Indonesia. International Journal of Technology, Volume 10(4), pp. 854-861

Julianto, P.A., 2017. Indonesia 5 Great World Shoe Exporter. Available Online at: https://ekonomi.kompas.com/2017/11/07/222300826/indonesia-5-besar-eksportir-alas-

kaki-dunia. Accessed on 26 November 2018

Kim, Y., Park, J., Park, M., 2016. Creating a Culture of Prevention in Occupational Safety and Health Practice. Safety and Health Work, Volume 7(2), pp. 89-96

Kines, P., Lappalainen, J., Mikkelsen, K.L., Olsen, E., Pousette, A., Tharaldsen, J., Tomasson, K., Törner, M., 2011. Nordic Safety Climate Questionnaire (NOSACQ-50): A New Tool for Diagnosing Occupational Safety Climate. International Journal of Industrial Ergonomics, Volume 41(6), pp. 634-646 
Lalko, J.F., Kimber, I., Dearman, R.J., Gerberick, G.F., Sarlo, K., Api, A.M., 2011. Chemical Reactivity Measurements: Potential for Characterization of Respiratory Chemical Allergens. Toxicology in Vitro, Volume 25(2), pp. 433-445

Lim, S.K., Shin, H.S., Yoon, K.S., Kwack, S.J., Um, Y.M., Hyeon, J.H., Kwak, H.M., Kim, J.Y., Roh, T.H., Lim, D.S., Shin, M.K., Choi, S.M., Kim, H.S., Lee, B.M., 2014. Risk Assessment of Volatile Organic Compounds Benzene, Toluene, Ethylbenzene, and Xylene (BTEX) in Consumer Products. Journal Toxicology and Environmental Health, Part A, Volume 77(2224), pp. 1502-1521

Listyani, M., Faisal, F., 2014. Corporate Social Responsibility Disclosure Practices of Indonesia Companies. Doctoral dissertation, Faculty of Economics and Business, Diponegoro University, Bandung, Indonesia

Markkanen, P.K., 2004. Occupational Safety and Health in Indonesia. ILO: Manila, Philippines

Matthews, R.A., Gallus, J.A., Henning, R.A., 2011. Participatory Ergonomics: Development of an Employee Assessment Questionnaire. Accident Analysis and Prevention, Volume 43(1), pp. 360-369

Mohammadfam, I., Kamalinia, M., Momeni, M., Golmohammadi, R., Hamidi, Y., Soltanian, A., 2017. Evaluation of the Quality of Occupational Health and Safety Management Systems based on Key Performance Indicators in Certified Organizations. Safety and Health Work, Volume 8(2), pp. 156-161

Nagai, R., Lefèvre, A.M.C., Lefèvre, F., Steluti, J., Teixeira, L.R., Zinn, L., Fischer, F.M., 2007. Knowledge and Practices by Adolescents in Preventing Occupational Injuries: A Qualitative Study. Revista de Saude Publica, Volume 41(3), pp. 404-411

NRCWE, 2014, International Evaluation 2014: National Research Centre for the Working Environment, Denmark

Penman, T.D., Christie, F.J., Andersen, A.N., Bradstock, R.A., Cary, G.J., Henderson, M.K., Price, O.F., Tran, C., Wardle, G.M., Williams, R.J., York, A., 2011. Prescribed Burning: How Can It Work to Conserve the Things We Value? International Journal of Wildland Fire, Volume 20(6), pp. 721-733

Seim, R., Broberg, O., 2010. Participatory Workspace Design: A New Approach for Ergonomists? International Journal of Industrial Ergonomics, Volume 40(1), pp. 25-33

Siswanto, D., Lestari, V., Iridiastadi, H., 2017. Evaluation of Machinist's Fatigue at PT. Kereta Api Persero DAOP II Bandung. International Journal of Technology, Volume 8(2), pp. 262 271

Van Eerd, D., Cole, D., Irvin, E., Mahood, Q., Keown, K., Theberge, N., Village, J., St. Vincent, M., Cullen, K,L., 2010. Process and Implementation of Participatory Ergonomic Interventions: A Systematic Review. Ergonomics, Volume 53(10), pp. 1153-1166 